\title{
BMJ Open Women's self-reported experiences using misoprostol obtained from drug sellers: a prospective cohort study in Lagos State, Nigeria
}

\author{
Melissa Stillman (D) , ${ }^{1}$ Onikepe Owolabi (D) , ${ }^{1}$ Adesegun O Fatusi (D) ,,2 \\ Akanni I Akinyemi (D) , 3,4 Amanda L Berry (D) , ${ }^{1}$ Temitope P Erinfolami (D) ,,5 \\ Olalekan S Olagunju (D) , ${ }^{4,5}$ Heini Väisänen (D) , ${ }^{6}$ Akinrinola Bankole (i) ${ }^{1}$
}

To cite: Stillman M, Owolabi 0 , Fatusi A0, et al. Women's selfreported experiences using misoprostol obtained from drug sellers: a prospective cohort study in Lagos State, Nigeria. BMJ Open 2020;10:e034670. doi:10.1136/ bmjopen-2019-034670

- Prepublication history and additional material for this paper are available online. To view these files, please visit the journal online (http://dx.doi. org/10.1136/bmjopen-2019034670).

Received 30 September 2019 Revised 11 February 2020 Accepted 12 March 2020

Check for updates

(C) Author(s) (or their employer(s)) 2020. Re-use permitted under CC BY-NC. No commercial re-use. See rights and permissions. Published by BMJ.

For numbered affiliations see end of article.

Correspondence to

Ms Melissa Stillman;

mstillman@guttmacher.org

\section{ABSTRACT}

Objectives This study aimed to assess the safety and effectiveness of self-managed misoprostol abortions obtained outside of the formal health system in Lagos State, Nigeria.

Design This was a prospective cohort study among women using misoprostol-containing medications purchased from drug sellers. Three telephoneadministered surveys were conducted over 1 month. Setting Data were collected in 2018 in six local government areas in Lagos State.

Participants Drug sellers attempted to recruit all women who purchased misoprostol-containing medication. To remain in the study, participants had to be female and aged 18-49, and had to have purchased the medication for the purpose of abortion. Of 501 women initially recruited, 446 were eligible for the full study, and 394 completed all three surveys.

Primary and secondary outcome measures Using self-reported measures, we assessed the quality of information provided by drug sellers; the prevalence of potential complications; and the proportion with completed abortions.

Results Although drug sellers provided inadequate information about the pills, $94 \%$ of the sample reported a complete abortion without surgical intervention about 1 month after taking the medication. Assuming a conservative scenario where all individuals lost to follow-up had failed terminations, the completion rate dropped to $87 \%$. While 86 women reported physical symptoms suggestive of complications, only six of them reported wanting or needing health facility care and four subsequently obtained care. Conclusions Drug sellers are an important source of medical abortion in this setting. Despite the limitations of self-report, many women appear to have effectively selfadministered misoprostol. Additional research is needed to expand the evidence on the safety and effectiveness of self-use of misoprostol for abortion in restrictive settings, and to inform approaches that support the health and wellbeing of people who use this method of abortion.

\section{INTRODUCTION}

Globally, medical abortion (MA) has become an increasingly important method for people

\section{Strengths and limitations of this study}

Data from this study are the first prospectively collected data that capture people's experiences with, and the self-reported effectiveness of, self-managed misoprostol abortion in a legally restrictive setting in sub-Saharan Africa.

- This study used novel recruitment and retention approaches: drug sellers were the source of recruitment, which leveraged existing client-provider relationships; unregistered mobile phones were distributed to participants to mitigate fears around potential loss of privacy; text messages were sent to participants periodically in between interviews, which improved engagement and likely contributed to the study's relatively high follow-up rate.

- The follow-up period for this study was 1 month, which is longer than that of previous studies, thus allowing more time for the medication to work and potentially resulting in a more accurate selfassessment of the medications' effectiveness.

- This study relied on misoprostol users' self-report for our primary outcomes, and although we believe participants are capable of describing changes in their own bodies, it is difficult to determine the extent to which our findings will correlate with data collected under clinical experimental conditions.

- The study sites were purposively selected, and the sample could only include clients who obtained misoprostol from drug sellers willing to participate in the study and who may be different from other drug sellers in unknown ways, therefore our findings are not generalisable to the entire population of the state and country.

seeking to terminate a pregnancy. ${ }^{1}$ While mifepristone followed by misoprostol is the preferred MA regimen recommended by the WHO, misoprostol alone is recommended as a safe and effective alternative where mifepristone is not available. ${ }^{2} \mathrm{WHO}$ guidelines specify self-managed mifepristone and misoprostol as a viable approach for terminating 
pregnancies when users have access to adequate information and a trained healthcare provider. ${ }^{3}$ However, WHO has not yet recommended self-management of misoprostol alone because of limited evidence. In contexts in which abortion is illegal or highly restricted, mifepristone is unlikely to be approved by the government, and self-managed abortion with misoprostol alone is a critical option for individuals who may otherwise resort to other, unsafe, methods. ${ }^{1}$

Nigeria has a population estimated at 200 million in $2019,{ }^{4}$ and induced abortion is legally permitted only to save a woman's life. ${ }^{5}$ Despite the restrictive law, the rate of induced abortion in Nigeria was estimated at between 41.1 and 59.4 per 1000 women of reproductive age in $2017 .^{6}$ MA drugs, particularly misoprostol, have become more widely available in Nigeria in recent years. ${ }^{7-9}$ Nigeria has a large market of drug vendors serving informally as the first point of care for diverse health problems, and most medications can be procured without prescription. ${ }^{10}$ However, evidence from other studies suggests that drug sellers have poor knowledge of MA drugs, commonly sell medications without packaging or instructions and often provide inadequate or inaccurate information to women about medications, side effects and potential complications. ${ }^{11-16}$

There is currently a dearth of community-based evidence on people's experiences accessing misoprostol from drug sellers and the outcomes of self-managed abortions. Findings from a prospective cohort study with a very small sample of women who bought misoprostol from pharmacy workers in Bangladesh indicate that $75 \%$ of women reported complete abortions after 2 weeks, ${ }^{17}$ which is just below the range of expected effectiveness for misoprostol alone $(78 \%-90 \%) .{ }^{18-21}$ Studies from several countries in Latin America where abortion is legally restricted suggest that even if adequate information is not provided by drug sellers, information obtained through other means, such as hotlines, may reduce the potential risks of self-managed MA. ${ }^{12-24}$ The few studies in subSaharan Africa that attempted to assess health outcomes from use of misoprostol alone recruited patients presenting for postabortion care in health facilities, and therefore do not represent everyone who had used this method. ${ }^{9}{ }^{25}$ Prospective studies have the potential to provide stronger evidence but those that have attempted to explore these topics have reported challenges with the recruitment and follow-up of participants. ${ }^{1726}$

To address this research gap, we designed a prospective study to explore the experiences of women (people of all genders are capable of becoming pregnant and having abortions. We did not include questions related to gender identity in the surveys due to concerns related to cultural sensitivity and appropriateness. For the purpose of this study, our eligibility criteria included being a woman $15-49$ years old who had purchased misoprostol to terminate a pregnancy, and the word 'woman' was used in the consent form as well as the surveys. Based on these criteria, in addition to assumptions made by drug sellers and the interviewers, we refer to participants as 'women' in this paper) who self-manage abortion using misoprostol obtained from drug sellers in Lagos State, Nigeria. We investigated what dosages and information women receive when attempting to purchase misoprostol for abortion; what clinical effects they experience, including potential complications; if and how they assess completeness; and what proportion of women have completed abortions.

\section{METHODS}

\section{Study setting}

Data for this study were collected in six local government areas (LGA) in Lagos State. Lagos is the most populous city in Nigeria and constitutes one of the largest markets for MA nationally. The 20 LGAs in Lagos State were stratified into more urban and less urban based on population density. From each stratum, we purposively selected three that each had at least one higher level educational institution. We hypothesised that areas with higher level educational institutions would have greater market for misoprostol due to the concentration of females aged 20-29 and those with a secondary education or higher, populations that have a relatively higher estimated incidence of abortion in Nigeria. ${ }^{27}$

\section{Study design and data collection}

Field activities were organised into two major components: (1) a drug seller study, which included (A) a mapping of pharmacies and proprietary patent medicine vendors, herein referred to as drug sellers, and (B) a screener interview to identify those selling misoprostol for any reason; and (2) a prospective cohort study of women who purchased misoprostol, recruited by drug sellers.

\section{Identifying drug sellers who sell misoprostol}

Fieldworkers collected the names and Global Positioning System coordinates of all drug sellers in each LGA, generating the universe $(\mathrm{n}=968$; figure 1$)$. Thereafter, they visited every shop and conducted a screening interview to generate a list of drug sellers that reported selling misoprostol for any indication. Drug sellers who reported selling misoprostol $(n=340)$ were invited to recruit all women who purchased any misoprostol-containing medications, directly or through a proxy, for any reason over a 2-month period. In total, 227 drug sellers agreed to recruit women. See online supplementary appendix A for more details on recruitment procedures.

\section{Prospective cohort study of women}

Drug sellers assisted in recruiting women who bought misoprostol, or a misoprostol-containing drug, for any reason. Drug sellers provided a general explanation of the study, and asked everyone interested in participating if they agreed to be contacted by a member of the study team. Interviewers contacted willing participants 1-2 days after purchase of the medicine, explained the study in 


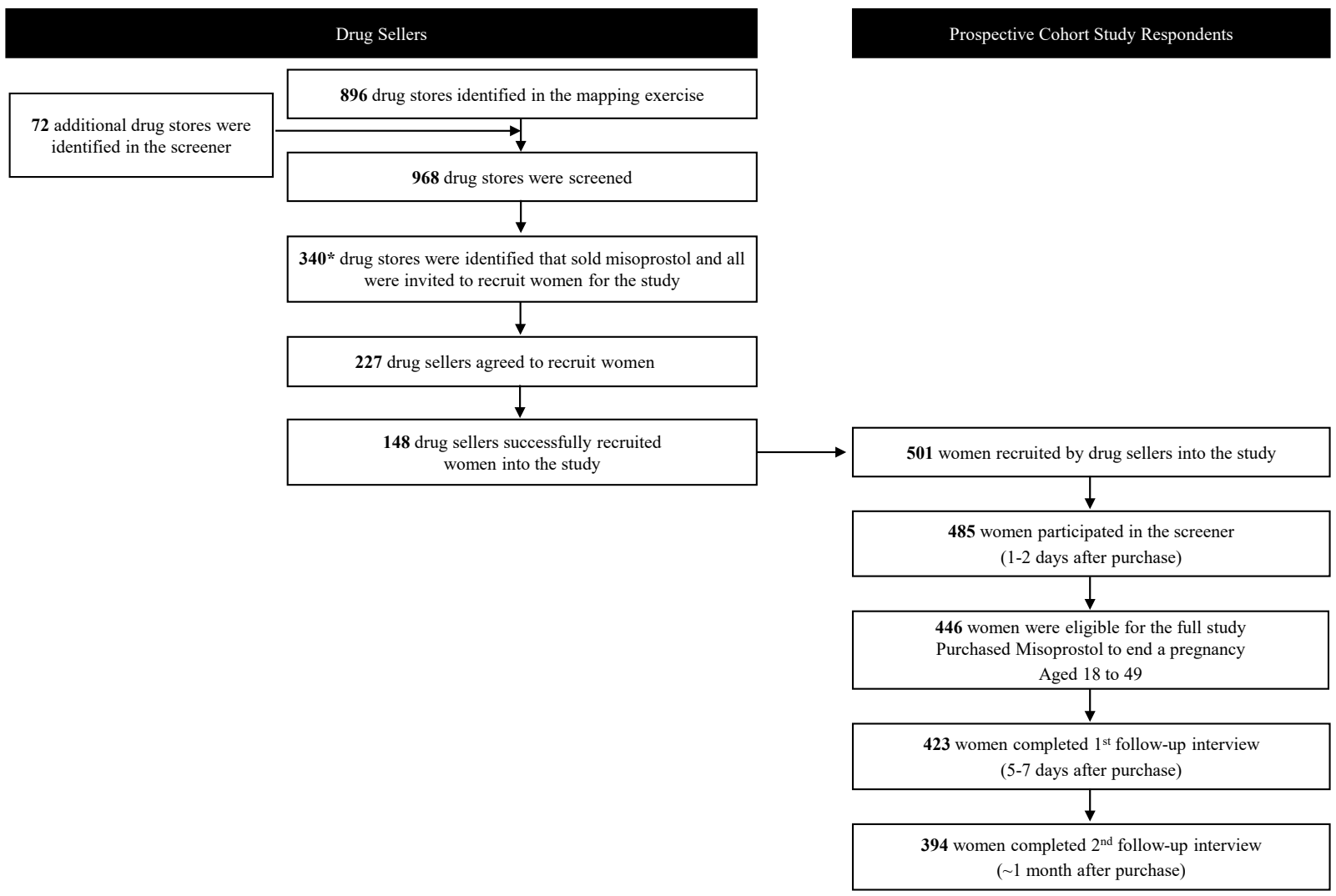

Figure 1 Sample of drug sellers, recruitment of women and retention throughout the study. *Sixteen additional drug sellers who initially denied selling misoprostol or refused to participate in the screener later agreed to recruit women.

detail and obtained informed consent to participate prior to conducting a telephone screener to determine eligibility. Only women aged 18-49 who bought misoprostol specifically to terminate a pregnancy were eligible for inclusion. Eligible women were invited to participate in two additional rounds of surveys using structured questionnaires administered by telephone over approximately 1 month.

A first follow-up interview was conducted 5-7 days after screening to identify the medications purchased, establish if and how the woman used the medication and ask about her interaction with the drug seller at the time of purchase. A second follow-up interview was conducted 3 weeks later ( 1 month after purchasing the medication) to understand women's self-reported health outcomes after taking the medication, how women assessed the completion of their abortions, support during the abortion process and women's willingness to recommend misoprostol to friends or use it again.

Data for the drug seller screening were collected in person by trained male fieldworkers and data from the women were collected over the telephone by female fieldworkers trained by the study team in sensitive interviewing techniques. All data were collected using the mobile data collection application SurveyCTO on password-protected and encrypted Android tablets and stored on a secure server accessible only to the research team. Women's informed consent was obtained prior to each interview, and permission to be contacted again for the next follow-up interview was given at the end of the screener and first follow-up interviews. Women's identities were confirmed at each interview using a unique identification number, password or nickname provided at the time of recruitment.

Interviewers did not have medical training and did not give advice about any potential complications or directly answer health-related questions at any point in the women's interviews. During the screener or first follow-up interview, respondents who asked for medical advice or who described symptoms that could indicate a serious health problem were provided with the telephone numbers for the Marie Stopes Nigeria hotline and the accident and emergency unit of the Lagos State University Teaching Hospital. All participants in the study were given this contact information after completion of the second follow-up interview, in case they had additional medical questions. Data collection occurred between April and October 2018. A description of the study and the study tools are on Open Science Framework, and are accessible at https://osf.io/3akjx/?view_only=960f $46 \mathrm{~d} 7$ $56 f d 4 b b 189499$ e1fe5ae54a5.

\section{Patient and public involvement}

The study was supported by a Technical Advisory Group that provided input on the program of research. The advisory group, which consisted of medical doctors, local 
researchers and other experts in the field of sexual and reproductive health in Nigeria, provided input on the research questions, study design and tool development prior to the start of fieldwork. The advisory group provided feedback on the preliminary research findings and advice on messaging the results. The group will help plan dissemination activities, including the presentation of findings to participating drug sellers and other stakeholders.

\section{Study definitions}

The criteria used to define the following measures are described in detail in the online supplementary appendix B.

\section{Dosage}

Doses of less than $800 \mathrm{mcg}$ for misoprostol alone were classified as less than the WHO-recommended dose for first trimester abortions. ${ }^{2}$

\section{Route of administration}

An optimal route of misoprostol administration was defined as administering it buccally, sublingually or vaginally. ${ }^{28}$ A suboptimal route was one where women were given the option to swallow the misoprostol by mouth.

\section{Adequacy of information}

We created a 9-item score for the adequacy of information covered during the drug sellers' interactions with women. We included information considered to be reasonably necessary, based on medical literature, for women to successfully self-manage abortion. We allocated each item one point if the information was provided and created the index by adding up the total number of points.

\section{Warning signs of potential complications}

Warning signs of complications were assessed using selfreported symptoms after taking the medication and included excessive or greater than anticipated bleeding; or a combination of greater than anticipated abdominal pain or cramping, fever and chills, or vaginal discharge that could potentially indicate an infection.

\section{Analysis}

We conducted descriptive analyses to summarise women's sociodemographic characteristics; the quality of information provided by drug sellers; the prevalence of potential complications; the proportion who had complete terminations without additional medical interventions; and abortion strategies women would have employed had they not used misoprostol. All analyses were conducted using Stata V.15.1.

\section{RESULTS}

Of the 501 women recruited by drug sellers, 485 (97\%) were successfully contacted and screened by interviewers, 446 were eligible for the study (92\% of those screened) and 394 (88\% of all eligible women recruited) were successfully interviewed in both follow-up interviews (figure 1).
The data presented in the results are from the 394 women who completed both interviews, including a small proportion $(2 \%)$ that received mifepristone+misoprostol.

\section{Demographic characteristics of participants}

Among our final sample, more than half $(55 \%)$ were between the ages of 18 and 29, and $92 \%$ had completed senior secondary school while $38 \%$ had completed some higher education (table 1). About three-quarters (76\%) worked for a family or non-family-owned business, and $13 \%$ were students at the time they purchased the misoprostol. Half (50\%) were married or cohabiting, and 95\% purchased the drug themselves. Most respondents (83\%) had taken some kind of pregnancy test prior to going to the drug seller. For $85 \%$ of participants, this was their first pregnancy termination.

\section{Abortion attempts prior to recruitment}

A small proportion $(5 \%, \mathrm{n}=21)$ of the sample had made at least one other attempt to terminate the current pregnancy prior to being recruited into the study (online supplementary appendix $\mathrm{C}$, table 1). Of them, 12 had taken pills and 10 ingested herbal preparations. Six women who took pills did not know what pills they had taken, four had taken emergency contraception and two took an unspecified dose of misoprostol that was reported as ineffective.

\section{Medication types, determining eligibility and dosage}

On entering the drugstore, $51 \%$ of women told the drug sellers that they needed something to end a pregnancy, and 39\% said they wanted help to bring back a late menstrual period (table 2). More than half $(57 \%)$ reported that they had not known there were pills they could take to end a pregnancy prior to visiting the drug seller; $22 \%$ had heard about such pills from a friend or family member; and $7 \%-8 \%$ found out about them online $(n=33)$ or from a health professional $(n=28)$ (not shown). One-fourth of the sample (25\%) reported that they did not know what medication they purchased from the drug seller. Among those who knew what medication they purchased, a majority $(97 \%, \mathrm{n}=272)$ reported receiving just misoprostol from the drug seller, and 3\% $(n=7)$ received misoprostol in combination with mifepristone. Based on women's self-reports of the type and number of tablets purchased, we confirmed that $44 \%$ were sold less than the recommended dosage for effectiveness ( $<800 \mathrm{mcg}$ misoprostol), $20 \%$ received a dosage within the range of effectiveness and we were unable to assess the dosage for an additional $37 \%$ of the sample.

\section{Instructions received from the drug sellers}

Most of the sample $(78 \%)$ reported that they were given some instructions about how to take the medications, and nearly all women who received instructions followed them (table 3). Most women relied solely on drug sellers for information: $72 \%$ did not use any other source (not shown). 
Table 1 Demographic characteristics of women, type of drug sellers visited and who bought the pills, proportion of women who took a pregnancy test and previous experiences with abortion

\begin{tabular}{|c|c|c|}
\hline & \multicolumn{2}{|c|}{$\begin{array}{l}\text { Among women } \\
\text { who completed } \\
\text { both follow-up } \\
\text { interviews ( } n=394)\end{array}$} \\
\hline & $\%$ & $\mathbf{n}$ \\
\hline \multicolumn{3}{|l|}{ Age categories } \\
\hline $18-24$ & 22.8 & 90 \\
\hline 25-29 & 32.0 & 126 \\
\hline $30-34$ & 23.4 & 92 \\
\hline 35-39 & 16.0 & 63 \\
\hline $40-44$ & 5.1 & 20 \\
\hline $45-49$ & 0.8 & 3 \\
\hline Median age (IQR) & 28 & (25-33) \\
\hline \multicolumn{3}{|l|}{ Parity* } \\
\hline No children & 33.5 & 76 \\
\hline 1-2 children & 37.4 & 85 \\
\hline $3+$ children & 29.1 & 66 \\
\hline Mean (SD) & 1.6 & $(1.5)$ \\
\hline
\end{tabular}

Highest level of education completed

\begin{tabular}{|c|c|c|}
\hline No schooling or incomplete primary & 0.8 & 3 \\
\hline Primary/junior secondary school & 7.4 & 29 \\
\hline Senior secondary school & 54.1 & 213 \\
\hline Some higher education (or more) & 37.8 & 149 \\
\hline \multicolumn{3}{|l|}{ Employment } \\
\hline $\begin{array}{l}\text { Work for someone else/non-family } \\
\text { business }\end{array}$ & 51.5 & 203 \\
\hline
\end{tabular}

\begin{tabular}{lrr} 
Work for own/family business & 24.1 & 95 \\
Housewife & 3.8 & 15 \\
Student & 13.2 & 52 \\
Unemployed & 7.4 & 29 \\
Relationship status & & \\
Currently married or cohabiting & 50.0 & 197 \\
Separated/divorced/widowed & 5.1 & 20 \\
Never married and never lived & 44.9 & 177 \\
together with a man & & \\
Local government area of recruitment & & \\
Lagos Mainland & 17.0 & 67 \\
Ojo & 18.3 & 72 \\
Oshodi-lsolo & 16.2 & 64 \\
Epe & 8.9 & 35 \\
\hline lkorodu & 24.4 & 96 \\
Ibeju Lekki & 15.2 & 60
\end{tabular}

Women who went to each type of drug seller

\begin{tabular}{lll} 
Pharmacy & 40.6 & 160 \\
\hline & Continued
\end{tabular}

Table 1 Continued

\begin{tabular}{|c|c|c|}
\hline & \multicolumn{2}{|c|}{$\begin{array}{l}\text { Among women } \\
\text { who completed } \\
\text { both follow-up } \\
\text { interviews }(n=394)\end{array}$} \\
\hline & $\%$ & $\mathbf{n}$ \\
\hline $\begin{array}{l}\text { Proprietary patent medicine vendor } \\
\text { (PPMV) }\end{array}$ & 59.4 & 234 \\
\hline \multicolumn{3}{|l|}{ Who purchased the medicine } \\
\hline Medicines bought by the woman & 95.2 & 375 \\
\hline Medicines bought by someone else & 4.8 & 19 \\
\hline \multicolumn{3}{|l|}{ Previous pregnancy terminations } \\
\hline No, has not ended a prior pregnancy & 84.5 & 333 \\
\hline Yes, has ended a prior pregnancy & 15.5 & 61 \\
\hline \multicolumn{3}{|l|}{$\begin{array}{l}\% \text { of women who took each type of } \\
\text { pregnancy test when they suspected } \\
\text { they were pregnant } †\end{array}$} \\
\hline Confirmation via test with a doctor & 20.8 & 82 \\
\hline Confirmation via test at a laboratory & 17.5 & 69 \\
\hline Self-administered urine test & 54.6 & 215 \\
\hline No test & 17.0 & 67 \\
\hline
\end{tabular}

*Data on parity were only from a subset of the sample $(n=227)$. †Multiple responses were allowed.

On average, women reported that drug sellers covered three of nine items we considered necessary for successful self-management of abortion using misoprostol (table 3). A relatively high proportion reported that drug sellers attempted to assess their eligibility: $74 \%$ were asked if they had confirmed their pregnancy with a test, and $79 \%$ were asked the timing of their last menstrual period. However, fewer reported being given information about what clinical symptoms to anticipate as a normal part of the abortion process; $67 \%$ and $35 \%$ reported being told that they could expect some bleeding or cramping, respectively. Only 51 women (13\%) were told about severe bleeding that could indicate a potential complication.

\section{Women's experiences of warning signs after taking the medication and subsequent care seeking}

Most women did not report adverse events after taking the medication. However, 77 women (20\%) reported bleeding that we classified as potentially problematic, and 15 women (4\%) reported a combination of symptoms suggestive of infection (table 4). Six women were classified as having experienced symptoms of both. Among the 86 women with potentially problematic bleeding or symptoms of infection, $7 \%(\mathrm{n}=6)$ reported wanting or needing medical care, and $5 \%(n=4)$ sought care (not shown). One of the four reported receiving a blood transfusion and undergoing a surgical abortion procedure, while the rest were given painkillers, an ultrasound or blood test.

Overall, 29 women in the study (7\%) reported wanting or needing medical care after taking the pills, and 24 
Table 2 Women's experiences interacting with the drug seller, types of medications, dosages and administration routes

\begin{tabular}{|c|c|c|}
\hline & \multicolumn{2}{|c|}{$\begin{array}{l}\text { Women who } \\
\text { completed both } \\
\text { follow-up interviews } \\
(n=394)\end{array}$} \\
\hline & $\%$ & $\mathrm{n}$ \\
\hline \multicolumn{3}{|l|}{$\begin{array}{l}\text { How women presented themselves to the drug } \\
\text { seller* }\end{array}$} \\
\hline $\begin{array}{l}\text { Told drug seller she wanted to end a } \\
\text { pregnancy. }\end{array}$ & 50.5 & 199 \\
\hline $\begin{array}{l}\text { Told drug seller she wanted to purchase } \\
\text { misoprostol or other specific brand name } \\
\text { medicine. }\end{array}$ & 16.2 & 64 \\
\hline $\begin{array}{l}\text { Told the drug seller she wanted to bring back } \\
\text { a late period. }\end{array}$ & 39.3 & 155 \\
\hline Told drug seller something else. & 1.3 & 5 \\
\hline \multicolumn{3}{|l|}{ Types of medicine women reported receiving $\dagger$} \\
\hline Misoprostol & 69.0 & 272 \\
\hline Misoprostol+mifepristone & 1.8 & 7 \\
\hline Unknown medicineł & 25.4 & 100 \\
\hline Missing & 3.8 & 15 \\
\hline \multicolumn{3}{|l|}{ Dosage of medication prescribed by drug seller§ } \\
\hline $\begin{array}{l}\text { Less than the WHO-recommended dosage } \\
(<800 \text { mcg misoprostol) }\end{array}$ & 43.7 & 172 \\
\hline 800 mcg misoprostol & 17.0 & 67 \\
\hline $1000-1400$ mcg misoprostol & 1.3 & 5 \\
\hline $1600-2400$ mcg misoprostol & 0.5 & 2 \\
\hline $200 \mathrm{mg}$ mifepristone and $800 \mathrm{mcg}$ misoprostol & 0.8 & 3 \\
\hline Not assessed & 36.8 & 145 \\
\hline
\end{tabular}

Routes of administration of the medication

prescribed by drug seller

\begin{tabular}{|c|c|c|}
\hline Suboptimal route (oral misoprostol) & 38.6 & 152 \\
\hline $\begin{array}{l}\text { Optimal route (buccal, vaginal or sublingual } \\
\text { misoprostol) }\end{array}$ & 19.0 & 75 \\
\hline Drug seller did not say & 0.3 & 1 \\
\hline Not assessed & 42.1 & 166 \\
\hline
\end{tabular}

${ }^{*}$ Multiple responses were allowed.

†Data on types of medicine received are not available for 15 women due to missing responses.

f'Unknown' means the woman did not know what medication she took, either because she was never told or because she could not remember. Although the medication was unknown to her, it still could have been misoprostol or another abortifacient.

\$The medication dosage could only be assessed among women who answered specific questions about the numbers of each type of pills they were given, and who either knew what medication(s) they were given or for whom we were able to, with reasonable confidence, parse out what medication(s) they were given based on their answers to related questions. IThe administration route could only be assessed among women for whom we could identify the medication(s) given. Since WHO guidelines recommend that mifepristone be administered orally and misoprostol be administered buccally, vaginally or sublingually, any administration route instructions that diverge from these recommendations are considered suboptimal.

$(6 \%)$ actually sought care (not shown). Few women (25\%, $\mathrm{n}=97$ ) were given any information from drug sellers about seeking postabortion care. However, $48 \%(n=14)$ of those who reported wanting or needing care also reported they had been told during their initial interaction with the
Table 3 Per cent of women who reported drug sellers providing information about misoprostol or asking questions to assess eligibility for misoprostol prior to purchase

\begin{tabular}{|c|c|c|}
\hline & \multicolumn{2}{|c|}{$\begin{array}{l}\text { Among women who } \\
\text { completed both follow-up } \\
\text { interviews ( } n=394)\end{array}$} \\
\hline & $\%$ & $\mathbf{n}$ \\
\hline $\begin{array}{l}\text { Women who received any instructions } \\
\text { from the drug seller about how to take } \\
\text { the medication }\end{array}$ & 77.9 & 307 \\
\hline \multicolumn{3}{|l|}{$\begin{array}{l}\text { Women who took tablets according to } \\
\text { drug sellers' instructions }\end{array}$} \\
\hline Followed instructions. & 75.9 & 299 \\
\hline Did not follow instructions. & 2.0 & 8 \\
\hline Did not receive instructions. & 22.1 & 87 \\
\hline \multicolumn{3}{|l|}{$\begin{array}{l}\text { Women reporting the following items } \\
\text { were covered during the interaction } \\
\text { with the drug seller }\end{array}$} \\
\hline $\begin{array}{l}\text { Asked timing of last menstrual } \\
\text { period. }\end{array}$ & 79.4 & 313 \\
\hline Asked if she took a pregnancy test. & 74.1 & 292 \\
\hline $\begin{array}{l}\text { Informed that bleeding is an } \\
\text { anticipated effect. }\end{array}$ & 66.5 & 262 \\
\hline $\begin{array}{l}\text { Informed that cramping is an } \\
\text { anticipated effect. }\end{array}$ & 35.3 & 139 \\
\hline $\begin{array}{l}\text { Informed that severe bleeding could } \\
\text { indicate a potential complication. }\end{array}$ & 12.9 & 51 \\
\hline $\begin{array}{l}\text { Informed that severe and persistent } \\
\text { abdominal pain could indicate a } \\
\text { potential complication. }\end{array}$ & 3.0 & 12 \\
\hline $\begin{array}{l}\text { Informed about use of pain } \\
\text { medication. }\end{array}$ & 28.2 & 111 \\
\hline $\begin{array}{l}\text { Informed of potential allergic } \\
\text { reactions. }\end{array}$ & 7.1 & 28 \\
\hline Informed of contraindications. & 22.8 & 90 \\
\hline
\end{tabular}

Number of items listed above that were covered in women's interaction with drug sellers

\begin{tabular}{lcc} 
No core information & 9.6 & 38 \\
\hline 1-3 items & 42.4 & 167 \\
$4-6$ items & 45.2 & 178 \\
\hline 7-8 items & 2.8 & 11 \\
\hline 9 items & - & - \\
& Mean & SD \\
$\begin{array}{lcc}\text { Adequacy of information scale score } \\
\text { (out of } 9 \text { items) }\end{array}$ & 3.3 & 1.8 \\
\hline
\end{tabular}

drug seller that they may need to seek medical attention for potential complications, compared with $23 \%(\mathrm{n}=84)$ of those who did not report needing follow-up care. Most women who sought care were given pain medication, or underwent an ultrasound, suggesting that they might not have presented with serious complications. One woman reported receiving a blood transfusion, and seven women were treated with a surgical abortion procedure.

\section{Participants' assessment of abortion completeness}

At the time of the second follow-up interview, around 1 month after taking the pills, $95 \%$ of women reported 
Table 4 Women's experiences of potential complications after using medications obtained from drug sellers

\section{Among women who completed both follow-up interviews $(n=394)$}

Women who experienced warning signs of potential complications

\begin{tabular}{lcc} 
& \% & n \\
\cline { 2 - 3 } Bleeding* $^{*}$ & 19.5 & 77 \\
$\begin{array}{l}\text { Cramping/abdominal } \\
\text { pain } †\end{array}$ & 2.0 & 8 \\
Fever/chills $\ddagger$ & 1.3 & 5 \\
$\begin{array}{l}\text { Foul smelling or coloured } \\
\text { vaginal discharge§ }\end{array}$ & 0.5 & 2 \\
\begin{tabular}{l} 
Postabortion infectionๆ \\
\hline
\end{tabular} & 3.8 & 15 \\
\hline
\end{tabular}

*Bleeding that could indicate potential complications is categorised as bleeding that soaks through more than two regular-sized pads in 2 hours, lasting for 12 hours after taking the medication. †Abdominal pain and cramping that could indicate potential complications are categorised as follows: abdominal pain selfreported as greater than 5 on a 1-10 pain scale that lasted more than 24 hours after taking the medication and was not alleviated by taking pain medication, or abdominal pain self-reported as greater than 5 on a 1-10 pain scale that occurs with nausea and (vomiting or diarrhoea) that lasted more than 24 hours after taking the medication, or abdominal pain at the time of the last interview ( 1 month after taking the medication), which was rated qualitatively by women as being 'moderate' or 'severe' or greater than 5 on the 1-10 pain scale and that had either lasted more than 6 days, or had not improved over time.

‡Fever and chills that could indicate potential complications are categorised as follows: fever or chills that lasted more than 24 hours after taking the medication, or any fever or chills still experienced at the time of the last interview ( 1 month after taking the medication).

§Foul-smelling or discoloured vaginal discharge that could indicate potential complications is categorised as follows: foul smelling or discoloured (not clear or white) discharge after taking the medication, or foul smelling or discoloured discharge at the time of the last interview that had either lasted for more than 6 days or had not improved over time.

IPostabortion infection was characterised as a combination of problematic abdominal pain or cramping, fever and chills, or vaginal discharge.

that they were no longer pregnant (table 5). The most common way women assessed the completeness of the abortion was by the return of their menstrual period (54\%). Three hundred and sixty-nine women (94\%) reported a complete abortion without any additional medical intervention about 1 month after taking the pills. Completion rates did not substantially vary according to the dosages women reported taking: $93 \%(n=160)$ of women who we confirmed received less than $800 \mathrm{mcg}$ of misoprostol reported complete abortions versus $97 \%$ $(\mathrm{n}=65)$ of women who received $800 \mathrm{mcg}$ (online supplementary appendix $\mathrm{C}$, table 3). If we assume $50 \%$ of the women lost to follow-up had a successful termination, then $91 \%$ of all 423 eligible women had a complete
Table 5 Women's perceptions of pregnancy continuation and how they assessed the completeness of the abortion process

\begin{tabular}{|c|c|c|}
\hline & \multicolumn{2}{|c|}{$\begin{array}{l}\text { Among women who completed both } \\
\text { follow-up interviews }(n=394)\end{array}$} \\
\hline & $\%$ & $n$ \\
\hline $\begin{array}{l}\text { Women who reported } \\
\text { that they were no longer } \\
\text { pregnant at the time of the } \\
\text { second follow-up interview }\end{array}$ & 95.4 & 376 \\
\hline \multicolumn{3}{|l|}{$\begin{array}{l}\text { Reasons given for } \\
\text { believing pregnancy has } \\
\text { ended }(n=376)^{\star}\end{array}$} \\
\hline $\begin{array}{l}\text { Woman's period } \\
\text { returned. }\end{array}$ & 53.7 & 202 \\
\hline $\begin{array}{l}\text { Woman took a urine } \\
\text { pregnancy test at home. }\end{array}$ & 33.2 & 125 \\
\hline $\begin{array}{l}\text { Woman no longer has } \\
\text { pregnancy symptoms. }\end{array}$ & 24.7 & 93 \\
\hline $\begin{array}{l}\text { Woman took a blood } \\
\text { pregnancy test. }\end{array}$ & 16.0 & 60 \\
\hline $\begin{array}{l}\text { Woman passed the } \\
\text { products of conception. }\end{array}$ & 13.3 & 50 \\
\hline $\begin{array}{l}\text { Woman took a urine } \\
\text { pregnancy test at a } \\
\text { facility. }\end{array}$ & 5.1 & 19 \\
\hline $\begin{array}{l}\text { Woman had a } \\
\text { sonogram/ultrasound. }\end{array}$ & 4.0 & 15 \\
\hline $\begin{array}{l}\text { Woman got cleaned } \\
\text { at a facility/surgical } \\
\text { intervention. }\end{array}$ & 1.9 & 7 \\
\hline Other. & 0.8 & 3 \\
\hline $\begin{array}{l}\text { Women who reported a } \\
\text { complete abortion without } \\
\text { surgical intervention }\end{array}$ & 93.7 & 369 \\
\hline
\end{tabular}

*Multiple responses were allowed.

abortion, and if we assume none of them had a successful termination the rate of complete abortion drops to $87 \%$ (online supplementary appendix C, table 4).

\section{Alternatives to using misoprostol and willingness to use it again or recommend it to a friend in the future}

Sixty per cent of women reported that they would have gone to a health facility for help had they not had access to misoprostol (not shown). Twenty-two women $(6 \%)$ said they would have gone to a traditional practitioner, 17 would have drunk chemicals, 4 would have done excessive exercise and 2 reported that they would have inserted objects to self-induce abortion. About one-fourth of women $(27 \%, \mathrm{n}=105)$ said they would have done nothing.

Seventy per cent of women in the study reported that they would use misoprostol again. Of those who would not, $47 \%(\mathrm{n}=56)$ said they would not terminate another pregnancy at all. Others (13\%-16\%) thought that it would damage their health or fertility, reported that it was too painful or that they did not like the experience. Nevertheless, $85 \%$ of participants reported that they would recommend misoprostol to a friend. 


\section{DISCUSSION}

To our knowledge, this is the first prospective study examining the experiences and health outcomes of women obtaining misoprostol from drug sellers in sub-Saharan Africa. Around two-thirds of eligible drug sellers were willing to recruit for the study, and $88 \%$ of eligible women completed the screener and both follow-up interviews.

Although about $60 \%$ of our sample was not aware of MA pills prior to visiting the drug seller, for nearly everyone this encounter was their first and only attempt to end their pregnancy. Most women visited the drug seller by themselves, and a majority of them appeared to have been comfortable explicitly asking drug sellers for help to induce an abortion. Most women in our study relied on their interaction with the drug sellers as their only source of information, reported trusting the information drug sellers gave them about the drugs and following their instructions for use. More than one-fourth reported that they would have had an unwanted birth had they not had access to misoprostol, suggesting they would have lost the opportunity to achieve their preferred family size or their desired timing of giving birth. Additionally, for nearly $9 \%$ of women, having access to misoprostol was essential to avoid self-induction with highly unsafe methods such as sharp objects inserted into the vagina, drinking chemical substances or another method obtained from an herbalist or other traditional practitioner. Further, the majority of women reported that they would recommend misoprostol abortion to a friend, and, if necessary, use it in the future, suggesting high levels of satisfaction with this method of abortion. These findings suggest a relatively high level of autonomy for abortion care seeking among our sample compared with other studies and indicate the important role that drug sellers play as trusted sources of information and providers of MA in Lagos State. However, the appropriateness of the drug prescriptions and the quality of information provided to women by drug sellers were poor overall, as documented in other studies. ${ }^{12}$

Among women who completed both interviews, 94\% reported complete abortion without surgical intervention. This finding is consistent with findings from other studies that assessed the effectiveness of self-managed misoprostol-only abortion. ${ }^{29} 30$ We were unable to assess the dosage received and instructions given on routes of administration for $37 \%$ and $42 \%$ of the sample, respectively. Among those who we could assess, at least two-thirds appeared to have received less than the first trimester recommended dose of $800 \mathrm{mcg}$ misoprostol and/or were told they could ingest the misoprostol orally, which is a less effective route of administration than sublingually, buccally or vaginally. ${ }^{28}$ The medication's high level of effectiveness despite the low doses reportedly used could be partially explained if most pregnancies were in second trimester, during which time the uterus is more sensitive to lower doses of misoprostol. ${ }^{31}$ The perceived success of the method could also be attributed to the longer length of follow-up in our study: generally, studies assessing MA effectiveness have followed up women around 2 weeks or sooner after taking the medication. ${ }^{17} 32$ Allowing for a longer follow-up period ensured that the medication had sufficient time to work in the body, and may have improved its success rate. ${ }^{32}$ Overall, even in the most conservative outcome for women lost to follow-up, the completeness rate of self-managed abortions in our study was $87 \%$ (online supplementary appendix C, table 4), which is within the effectiveness range for misoprostol based on recommended protocols in clinical settings $(78 \%-90 \%) .^{18-21}$

WHO's task-sharing guidelines recognise that women have a role in self-management of the combined mifepristone and misoprostol abortion regimen if they have accurate information and access to a healthcare provider should they want or need at any point during the process, although pharmacy-alone provision is not explicitly recommended. ${ }^{3}$ However, no such self-management guidelines yet exist for misoprostol-only abortions, which was the regimen used by the majority of our study sample. We could not accurately assess their weeks of gestation; however, the majority of the sample had taken a pregnancy test, was able to follow instructions and, similar to findings from other studies, ${ }^{33}$ appeared to have been able to assess the completeness of termination. Almost all women retained for the duration of the study reported complete abortion at the 1-month follow-up. While most women did not report needing or wanting postabortion care, we were unable to clinically verify the proportion that actually experienced complications. The findings suggest that perceptions of needing care may be related to information, or lack thereof, they received from drug sellers about potential complications and care-seeking needs. Nearly half (48\%) of those who reported needing medical care had been warned by drug sellers about complications, compared with only $23 \%$ of those who did not report needing care. However, the results show that nearly all women who reported wanting or needing care were able to access it, and most of those who sought care were monitored or given pain medications, suggesting that they presented with symptoms that were either a normal part of the abortion process or that reflected very minor complications.

Our study had many methodological challenges and limitations. The study LGAs were purposively selected, so our sample was not representative of Lagos State. We had little information on women who dropped out and were hence unable to ascertain how they differed from women who completed the entire study. Our sample only included women who were recruited by drug sellers who admitted to selling misoprostol and then agreed to participate in recruiting women, and who may have had different practices from those who did not admit to selling or agree to recruit women, which could have potentially biased our results (online supplementary appendix $\mathrm{C}$, table 5). We were able to verify the medication purchased for about three-fourths of the women. However, we hypothesised that a majority of the women in our study obtained misoprostol because this was the criterion for recruitment on 
which we trained drug sellers, and we did not see many differences in key indicators between the women who we were able to verify had purchased misoprostol and those who we could not verify (online supplementary appendix C, table 2). Measures for dosage and route of administration were based on women's self-report of the number of pills they took and instructions they were given, which may have been subject to recall bias and/or misinterpretation. These limitations were, in part, balanced by the strengths of the study, including its prospective design and its focus on women's direct experiences rather than relying on third party reporting. However, our overall reliance on self-reported measures for many of our core outcomes makes it difficult to determine the extent to which our findings will correlate with clinical data and must be interpreted with caution.

\section{CONCLUSION}

Worldwide, there is a paucity of research assessing the processes by which women obtain MA (either the combined method or misoprostol alone) for selfmanagement of abortion and prospectively documenting their outcomes. Our success with drug seller engagement and women's recruitment is high compared with previous studies. ${ }^{17}{ }^{26}$ While this success may be due in part to the urban context of Lagos and the relatively liberal environment for drugstores and medication access generally in Nigeria, our experience suggests that prospective studies on misoprostol abortion in highly restrictive legal settings with similar attributes may be feasible. While our findings may not be generalisable to the entire female population in Lagos, they do provide valuable insights into the experiences of women who self-manage their abortions using misoprostol, from their own perspectives. The majority of our sample purchased misoprostol, took the medication according to the instructions, reported that drug sellers were their main source of information during the process and appeared to have been able to successfully complete their abortions with minimal complications. Recognising the limitations of self-reported outcomes, and given evidence from clinical trials suggesting that as many as $20 \%$ of women may experience an incomplete termination using misoprostol alone, it is an important harm reduction strategy to ensure that people who selfmanage their MAs have adequate and correct information on warning signs of complications as well as access to postabortion care. Interventions to improve drug sellers' knowledge of best practices related to MA may be an important part of the effort to improve their quality of services and the health and well-being of their clients, especially in similar settings where drug sellers are relied on for basic medical care. However, future research should explore ways to more objectively capture data relating to the duration of pregnancy, drug dosage and clinical outcomes in addition to documenting individuals' experiences using the method. It is likely that the self-use of misoprostol will remain an important option for people, especially where abortion is legally restricted. More research is needed to expand the evidence on the safety and effectiveness of self-managed misoprostol abortion in similarly restrictive contexts, and to help inform the development of approaches and mechanisms to facilitate optimal outcomes for those using this method.

\section{Author affiliations}

${ }^{1}$ Department of Research, Guttmacher Institute, New York, New York, USA

${ }^{2}$ Academy for Health Development (AHEAD), Ile-lfe, Nigeria

${ }^{3}$ Department of Global Health and Population, Harvard T H Chan School of Public Health, Boston, Massachusetts, United States

${ }^{4}$ Department of Demography and Social Statistics, Obafemi Awolowo University, Ile-lfe, Nigeria

${ }^{5}$ Centre for Research, Evaluation, Resources and Development (CRERD), Ile-lfe, Nigeria

${ }^{6}$ Department of Social Statistics and Demography, University of Southampton, Southampton, UK

Acknowledgements The authors thank the members of the Technical Advisory Committee for their guidance throughout the duration of the study: Professor Babalola Adeyemi (Obafemi Awolowo University), Dr Kayode Afolabi (Federal Ministry of Health, Nigeria), Dr Olanike Adedeji and Professor Olumuyiwa Odusanya (Lagos State University, College of Medicine). The authors also acknowledge Susheela Singh and Ann Moore of the Guttmacher Institute for their contributions to the study design and their review of the manuscript, and Heather Boonstra (Guttmacher Institute) and Colette Rose (formerly Guttmacher Institute) for their input on an earlier draft. This study benefited from input from a larger threecountry study team, including staff from Guttmacher Institute, Academy for Health Development (AHEAD, Nigeria), Centre for Research, Evaluation Resources and Development (CRERD, Nigeria), Oriéntame (Colombia) and Reconstra (Indonesia). Finally, the authors express their appreciation for all study participants.

Contributors $00, A B, M S, A O F$ and AIA participated in the conceptualisation of the project and designed the study. AOF, AIA, MS, 00, AB, ALB, TPE, OSO and HV participated in project planning. MS, ALB, 00 and TPE programmed the study tools into SurveyCTO for electronic data collection. AIA, TPE and OSO coordinated all aspects of fielding. AIA, AOF, TPE and OSO conducted the piloting of the study protocol and tools. AIA, TPE and OSO selected fieldworkers and organised the trainings. MS, AIA, TPE, OSO, AOF and HV co-led fieldwork trainings. AOF liaised with the Ministry of Health and relevant drug seller associations to get permission to conduct fieldwork at the local level. AOF and AIA convened the Technical Advisory Committee. MS, 00, TPE and ALB analysed the data. MS, 00, ALB, TPE and OSO wrote the first draft of the article; all other authors critically reviewed the draft, and MS led the revisions. The entire team contributed to the development of study tools, participated in the conceptualisation of the paper, and reviewed and approved the final version of the paper. All authors had full access to all the data in the study, and the corresponding author had final responsibility for the decision to submit for publication.

Funding The study on which this article is based was made possible by UK Aid from the UK Government (project number 203177-101), the Dutch Ministry of Foreign Affairs (activity number 4000000282) and an anonymous foundation.

Disclaimer The views expressed are those of the authors and do not necessarily reflect the positions and policies of the donors.

\section{Competing interests None declared.}

Patient and public involvement Patients and/or the public were involved in the design, or conduct, or reporting, or dissemination plans of this research. Refer to the Methods section for further details.

Patient consent for publication Not required.

Ethics approval The National Health Research Ethics Committee in Nigeria and the Institutional Review Board of Guttmacher Institute approved the study.

Provenance and peer review Not commissioned; externally peer reviewed. 
Data availability statement Data are available upon reasonable request. A member of the study team must be involved in the analysis of the data, and confidentiality of respondents will be protected at all times.

Open access This is an open access article distributed in accordance with the Creative Commons Attribution Non Commercial (CC BY-NC 4.0) license, which permits others to distribute, remix, adapt, build upon this work non-commercially, and license their derivative works on different terms, provided the original work is properly cited, appropriate credit is given, any changes made indicated, and the use is non-commercial. See: http://creativecommons.org/licenses/by-nc/4.0/.

\section{ORCID iDs}

Melissa Stillman http://orcid.org/0000-0002-1318-2419

Onikepe Owolabi http://orcid.org/0000-0002-4150-9976

Adesegun 0 Fatusi http://orcid.org/0000-0002-3893-8024

Akanni I Akinyemi http://orcid.org/0000-0001-8652-9359

Amanda L Berry http://orcid.org/0000-0001-9084-7771

Temitope P Erinfolami http://orcid.org/0000-0001-6576-398X

Olalekan S Olagunju http://orcid.org/0000-0001-8394-133X

Heini Väisänen http://orcid.org/0000-0002-5494-0415

Akinrinola Bankole http://orcid.org/0000-0003-3220-9477

\section{REFERENCES}

1 Singh S, Remez L, Sedgh G. Abortion worldwide 2017: uneven progress and unequal access. Guttmacher Institute, 2018.

2 World Health Organization. Medical management of abortion. Geneva: World Health Organization, 2018.

3 World Health Organization. Health worker roles in providing safe abortion care and post-abortion contraception. Geneva, Switzerland: World Health Organization, 2015.

4 United Nations, Department of Economic and Social Affairs, Population Division. World population prospects 2019. United Nations, 2019. https://population.un.org/wpp

5 Center for Reproductive Rights. The World's Abortion Laws Map. no date. Available: https://reproductiverights.org/worldabortionlaws

6 Bell S, Omoluabi E, Shankar M, et al. Abortion incidence and safety in Nigeria: findings from a population-based survey. Austin, Texas, 2019. Available: http://paa2019.populationassociation.org/uploads/ 190710 [Accessed 14 Aug 2019].

7 Akiode A, Fetters T, Okoh M, et al. The availability of misoprostol in pharmacies and patent medicine stores in two Nigerian cities. Ebonyi Med J 2010.

8 Jadesimi A, Okonofua FE. Tackling the unacceptable: Nigeria approves misoprostol for postpartum haemorrhage. J Fam Plann Reprod Health Care 2006;32:213-4.

9 Bello FA, Fawole B, Oluborode B, et al. Trends in misoprostol use and abortion complications: a cross-sectional study from nine referral hospitals in Nigeria. PLoS One 2018;13:e0209415.

10 Beyeler N, Liu J, Sieverding M. A systematic review of the role of proprietary and patent medicine vendors in healthcare provision in Nigeria. PLoS One 2015;10:e0117165.

11 Sneeringer RK, Billings DL, Ganatra B, et al. Roles of pharmacists in expanding access to safe and effective medical abortion in developing countries: a review of the literature. J Public Health Policy 2012;33:218-29.

12 Footman K, Keenan K, Reiss K, et al. Medical abortion provision by pharmacies and drug sellers in low- and middle-income countries: a systematic review. Stud Fam Plann 2018;49:57-70.

13 Hendrickson C, Fetters T, Mupeta S, et al. Client-pharmacy worker interactions regarding medical abortion in Zambia in 2009 and 2011. Int J Gynaecol Obstet 2016;132:214-8.

14 Reiss K, Footman K, Akora V, et al. Pharmacy workers' knowledge and provision of medication for termination of pregnancy in Kenya. $J$ Fam Plann Reprod Health Care 2016;42:208-12.
15 Reiss K, Footman K, Burke E, et al. Knowledge and provision of misoprostol among pharmacy workers in Senegal: a cross sectional study. BMC Pregnancy Childbirth 2017;17:211.

16 Huda FA, Mahmood HR, Alam A, et al. Provision of menstrual regulation with medication among pharmacies in three municipal districts of Bangladesh: a situation analysis. Contraception 2018;97:144-51.

17 Footman K, Scott R, Taleb F, et al. Feasibility of assessing the safety and effectiveness of menstrual regulation medications purchased from pharmacies in Bangladesh: a prospective cohort study. Contraception 2018;97:152-9.

18 Faúndes A, Fiala C, Tang OS, et al. Misoprostol for the termination of pregnancy up to 12 completed weeks of pregnancy. Int J Gynaecol Obstet 2007;99 Suppl 2:S172-7.

19 von Hertzen H, Piaggio G, Huong NTM, et al. Efficacy of two intervals and two routes of administration of misoprostol for termination of early pregnancy: a randomised controlled equivalence trial. Lancet 2007;369:1938-46.

20 Blum J, Raghavan S, Dabash R, et al. Comparison of misoprostolonly and combined mifepristone-misoprostol regimens for homebased early medical abortion in Tunisia and Vietnam. Int J Gynaecol Obstet 2012;118:166-71.

21 Raymond EG, Harrison MS, Weaver MA. Efficacy of misoprostol alone for first-trimester medical abortion: a systematic review. Obstet Gynecol 2019;133:137-47.

22 Drovetta RI. Safe abortion information hotlines: an effective strategy for increasing women's access to safe abortions in Latin America. Reprod Health Matters 2015;23:47-57.

23 Ramos S, Romero M, Aizenberg L. Women's experiences with the use of medical abortion in a legally restricted context: the case of Argentina. Reprod Health Matters 2014;22:4-15.

24 Palma Manríquez I, Moreno Standen C, Álvarez Carimoney A, et al. Experience of clandestine use of medical abortion among university students in Chile: a qualitative study. Contraception 2018;97:100-7.

25 Pourette D, Mattern C, Ratovoson R, et al. Complications with use of misoprostol for abortion in Madagascar: between ease of access and lack of information. Contraception 2018;97:116-21.

26 Brahmi D, Maxwell L, Collado ME, et al. Pharmacy recruitment of misoprostol users in Mexico: a feasibility study. Contraception 2014;90:299

27 PMA. PMA2020. 2018. Abortion Survey Results: Nigeria, 2020. https://www.pma2020.org/sites/default/files/AbortionModule_Brief 111518.pdf

28 Morris JL, Winikoff B, Dabash R, et al. Figo's updated recommendations for misoprostol used alone in gynecology and obstetrics. Int J Gynecol Obstet 2017;138:363-6.

29 Foster AM, Arnott G, Hobstetter M. Community-Based distribution of misoprostol for early abortion: evaluation of a program along the Thailand-Burma border. Contraception 2017:96:242-7.

30 Gerdts C, Jayaweera RT, Baum SE, et al. Second-Trimester medication abortion outside the clinic setting: an analysis of electronic client records from a safe abortion Hotline in Indonesia. BMJ Sex Reprod Health 2018;44:286-91.

31 Gemzell-Danielsson K, Lalitkumar S. Second trimester medical abortion with mifepristone-misoprostol and misoprostol alone: a review of methods and management. Reprod Health Matters 2008;16:162-72.

32 Moreno-Ruiz NL, Borgatta L, Yanow S, et al. Alternatives to mifepristone for early medical abortion. Int J Gynaecol Obstet 2007;96:212-8.

33 Schmidt-Hansen M, Cameron S, Lohr PA, et al. Follow-Up strategies to confirm the success of medical abortion of pregnancies up to 10 weeks' gestation: a systematic review with meta-analyses. Am J Obstet Gynecol 2019. doi:10.1016/j.ajog.2019.11.1244. [Epub ahead of print: 09 Nov 2019]. 